\title{
Enhanced down-regulation of ALCAM/CD166 in African-American Breast Cancer
}

\author{
Fang Tan', Marina Mosunjac², Amy L Adams ${ }^{3}$, Beverly Adade ${ }^{1}$, Oleyad Taye ${ }^{1}$, Yijuan Hu${ }^{4}$, Monica Rizzo ${ }^{5}$ \\ and Solomon F Ofori-Acquah ${ }^{1,6^{*}}$
}

\begin{abstract}
Background: Variation in tumor biology in African-American (AA) and Caucasian (CAU) women with breast cancer is poorly defined. Activated leukocyte cell adhesion molecule (ALCAM) is a bad prognostic factor of breast cancer yet it has never being studied in the AA population. We tested the hypothesis that ALCAM expression would be markedly lower in cases of AA breast cancer when compared to CAU.

Methods: Cases of breast cancer among AA $(n=78)$ and CAU $(n=95)$ women were studied. Immunohistochemical staining was used to semi-quantitatively score ALCAM expression in tumor and adjacent non-tumor breast tissues. Clinico-pathological characteristics including histological type, histological grade, tumor size, lymph node metastasis, estrogen receptor (ER), progesterone receptor (PR), and HER2-neu status were abstracted, and their association with ALCAM expression tested.

Results: Univariate analysis revealed that the level of ALCAM expression at intercellular junctions of primary tumors correlates with histological grade (AA; $p=0.04, C U A ; p=0.02$ ), ER status ( $A A ; p=0.0004, C A U ; p=0.0015$ ), PR status $(A A ; p=0.002$, CUA $p=0.034$ ) and triple-negative tumor status ( $A A ; p=0.0002, C A U ; p=0.0006$,) in both ethnic groups. Multivariate analysis demonstrated that ethnicity contribute significantly to ALCAM expression after accounting for basal-like subtype, age, histological grade, tumor size, and lymph node status. Compared to CAU tumors, the AA are 4 times more likely to have low ALCAM expression $(p=0.003)$.

Conclusions: Markedly low expression of ALCAM at sites of cell-cell contact in primary breast cancer tumors regardless of differentiation, size and lymph node involvement may contribute to the more aggressive phenotype of breast cancer among AA women.
\end{abstract}

Keywords: ALCAM, African-American, Caucasian, Breast cancer

\section{Background}

Breast cancer affects African-American (AA) women at a lower frequency than Caucasian (CAU) women, yet progression of the tumor and mortality from the disease is higher among AA [1]. This difference persists even after taking into account access to care, tumor characteristics, and treatments $[2,3]$. There are a few clear explanations for these ethnic disparities [4]. The overwhelming majority of studies aimed at understanding this disparity have

\footnotetext{
* Correspondence: sfo2@pitt.edu

${ }^{1}$ Aflac Cancer Center and Blood Disorders Service, Department of Pediatrics, Emory University School of Medicine, 2015 Uppergate Drive, Atlanta, GA 30322, USA

${ }^{6}$ Current address: University of Pittsburgh, 200 Lothrop Street, Pittsburgh, PA 15261, USA

Full list of author information is available at the end of the article
}

focused on socioeconomic and cultural differences, which clearly have significant health consequences across a broad spectrum of diseases, including cancer $[2,5,6]$. On the contrary, there is a paucity of studies on the potential role of heterogeneity in tumor biology in the health disparity of breast cancer in the US.

The discovery of molecular markers that influence prognostic or treatment outcome may help to understand the ethnic disparity in breast cancer in the US $[7,8]$. Adhesion molecules tethered at sites of cell-cell contact intimately influence cancer progression and the response to therapy, and are therefore, candidate molecules for understanding this disparity [9-12]. Activated leukocyte cell adhesion molecule (ALCAM/CD166), is an immunoglobulin cell 
adhesion molecule expressed by neuronal, endothelial, hematopoietic and epithelial cells [13-16]. We showed previously that ALCAM is recruited to sites of cell-cell contact in epithelium [17]. In a study of primary breast cancer tissues and non-neoplastic mammary tissue from the same mastectomies, we discovered that ALCAM mRNA was lower in tumors from patients who had metastases to regional lymph nodes and early mortality [18]. Other studies confirmed that loss of ALCAM function, due to reduced expression and/or protein mislocation is a bad prognostic marker in breast cancer [17-22]. ALCAM coalesces breast cancer cells together in homotypic interactions thus preventing interactions with neighboring endothelium, which may facilitate metastasis [23]. In support of this idea low ALCAM mRNA correlates with the development of skeletal metastasis [24].

Despite the significance of ALCAM in breast cancer this molecule has not previously been studied among AA women. In the current study, we tested the hypothesis that ALCAM expression is low in breast cancer tumors of AA women, and that this phenomenon may contribute to the more aggressive tumor phenotype in this patient population. We found that ALCAM was reduced or completely absent at intercellular junctions of most breast cancer tumors of AA women. On the contrary, the majority of tumors of CAU women had moderate to high ALCAM expression. This ethnic disparity was evident in tumors of similar histological grade, tumor size and lymph node. Thus, loss of ALCAM may contribute to the more aggressive phenotype of breast cancer among AA women.

\section{Methods}

\section{Patients and tissue blocks}

The study protocol was reviewed and approved by Emory University's Institutional Review Board (IRB) Committee. The consent forms were not required for this study. Patients included in this study were self-reported as AA and CAU diagnosed with invasive breast cancer. A total of 173 cases of invasive breast cancer (78 AA and $95 \mathrm{CAU}$ ) in Emory University hospital or Grady Memorial Hospital from 2007 to 2009 were studied. Tumor-related factors (Histological type, histological grade, tumor size and nodal status) were obtained from the independent abstraction of pathology reports. Stage at diagnosis was defined using American Joint Committee on Cancer Stage criteria that are in use during the case ascertainment period (20072009) [25]. Stage represents pathologic stage at the time of the first diagnostic procedure confirming invasive breast cancer and was divided into groups (I, II and III/IV). Archived formalin-fixed paraffin-embedded (FFPE) tissue blocks were retrieved and reviewed by the pathologist, who was blinded to ethnicity and other personal characteristics. The ER/PR status and HER2/neu status reported in patient pathology reports were determined by immunohistochemistry (IHC).

\section{Immunohistochemical analysis}

Formalin-fixed paraffin-embedded tissue sections were mounted on superfrost slides and stained using appropriate positive and negative controls as we have described previously $[18,19]$.

The sections $(5 \mu \mathrm{m})$ were de-paraffinized, rehydrated and processed for antigen retrieval using Dako Antigen Retrieval Solution. Tissue peroxidases were inactivated by treatment with $3 \% \mathrm{H}_{2} \mathrm{O}_{2}$ for $5 \mathrm{~min}$, and the sections pre-treated with antibody diluent solution containing $1 \%$ $\mathrm{BSA}$, followed by $40 \mathrm{~min}$ incubation at room temperature with primary antibodies for ALCAM (1:40 dilution, Novocastra Laboratories). Labeling was accomplished with biotinylated secondary antibodies and streptavidinHRP using Biotinylated Link Antibody kit (Dako North America Inc, Carpinteria, CA), AEC substrate chromogen, and counterstained with hematoxylin for $5 \mathrm{~min}$. Sections were mounted with aqueous media, examined using Olympus AX70 microscope and images were recorded with camera (Olympus U-CMAD3 DP70) and software (Olympus DP70/DP30 BW, ver.02.0201.147). Negative control tests were conducted with samples in the absence of primary antibody. Similarly, control paraffin slides with known negative or positive expression ALCAM were tested alongside of unknown samples.

\section{Evaluation of immunohistochemistry}

Stained tissue sections were independently examined in a blinded fashion by two clinical pathologists, who were blinded to clinical information and pathological parameters. ALCAM expression at intercellular junctions (i.e. membranous) and in the cytoplasm was evaluated separately. An immunoreactive score (IRS) based on the percentage of positive cells and staining intensity was applied. The percentage of positive cell scores were assigned according to the following scale: $0: 0 \% ; 1$ : 1-20\%; 2: 21-50\%; 3: 51-80\%; 4: >80\%. Staining intensity was scored semi-quantitatively as follows: 0 : none; 1 : mild; 2: moderate; and 3: intense. A total score for each membrane and cytoplasmic staining was then obtained (ranging from 0 to 12). Results were summed up and divided by the number of evaluation procedures to receive an average.

\section{Statistical analysis}

Data analyses were performed using SPSS (SPSS Inc, Chicago, IL, USA) and GraphPad Prism Software (version 5.0). Fisher's exact or chi-square tests were used to evaluate differences in clinico-pathological characteristics between AA and CAU women and correlations between expression of ALCAM (low or high) and clinic-pathological 
Table 1 Clinical and pathological characteristics of AA and CAU breast cancer in Atlanta

\begin{tabular}{|c|c|c|c|c|c|}
\hline \multirow[t]{2}{*}{ Characteristics } & \multicolumn{2}{|c|}{ CAU $(n=95)$} & \multicolumn{2}{|c|}{ AA $(n=78)$} & \multirow[t]{2}{*}{$p$ value } \\
\hline & $\mathrm{n}$ & $\%$ & $\mathrm{n}$ & $\%$ & \\
\hline Age at diagnosis & & & & & 0.99 \\
\hline$\leq 50$ years & 29 & 30.5 & 23 & 29.5 & \\
\hline$>50$ years & 66 & 69.5 & 55 & 70.5 & \\
\hline Histological type & & & & & $0.003^{*}$ \\
\hline Ductal & 74 & 77.8 & 76 & 97.4 & \\
\hline Lobular & 7 & 7.4 & 2 & 2.6 & \\
\hline Ductal/Lobular & 7 & 7.4 & 0 & & \\
\hline Missing & 7 & 7.4 & & & \\
\hline Histological grade & & & & & 0.069 \\
\hline G1 & 29 & 30.5 & 16 & 20.5 & \\
\hline G2 & 44 & 46.3 & 29 & 37.2 & \\
\hline G3 & 17 & 17.9 & 24 & 30.8 & \\
\hline Missing & 5 & 5.3 & 9 & 11.5 & \\
\hline Tumor size & & & & & $0.026^{*}$ \\
\hline $\mathrm{T} 1$ & 69 & 72.6 & 34 & 43.6 & \\
\hline $\mathrm{T} 2$ & 15 & 15.8 & 20 & 25.6 & \\
\hline T3-T4 & 6 & 6.3 & 7 & 9.0 & \\
\hline Missing & 5 & 5.3 & 17 & 21.8 & \\
\hline Lymph node status & & & & & 0.68 \\
\hline Negative & 48 & 50.5 & 38 & 48.7 & \\
\hline Positive & 25 & 26.3 & 23 & 29.5 & \\
\hline Missing & 22 & 23.2 & 17 & 21.8 & \\
\hline AJCC stage & & & & & 0.65 \\
\hline । & 40 & 42.1 & 28 & 35.9 & \\
\hline ॥ & 22 & 23.2 & 18 & 23.1 & \\
\hline III-IV & 11 & 11.5 & 12 & 15.4 & \\
\hline Missing & 22 & 23.2 & 20 & 25.6 & \\
\hline ER status & & & & & $0.001^{*}$ \\
\hline Negative & 15 & 15.8 & 30 & 38.5 & \\
\hline Positive & 70 & 73.7 & 45 & 57.7 & \\
\hline Missing & 10 & 10.5 & 3 & 3.8 & \\
\hline PR status & & & & & 0.081 \\
\hline Negative & 28 & 29.5 & 34 & 43.6 & \\
\hline Positive & 57 & 60 & 41 & 52.6 & \\
\hline Missing & 10 & 10.5 & 3 & 3.8 & \\
\hline HER2-neu status & & & & & 0.13 \\
\hline Negative & 67 & 70.5 & 65 & 83.4 & \\
\hline Positive & 19 & 20 & 9 & 11.5 & \\
\hline Missing & 9 & 9.5 & 4 & 5.1 & \\
\hline
\end{tabular}

Table 1 Clinical and pathological characteristics of AA and CAU breast cancer in Atlanta (Continued)

\begin{tabular}{cccccc}
\hline Triple negative & & & & & $0.0008^{*}$ \\
Yes & 10 & 10.5 & 25 & 32.0 & \\
No & 74 & 77.9 & 51 & 65.4 & \\
Missing & 11 & 11.6 & 2 & 2.6 & \\
\hline
\end{tabular}

AJCC: American Joint Committee on Cancer; CAU: Caucasian; AA: African-American ER/PR: estrogen/progesterone receptor; HER2-NEU: human epidermal growth receptor $2 .{ }^{*}$ Age-adjusted.

characteristics. The association of ALCAM expression with ethnicity, age, histological grade, tumor size, lymph node status, ER/PR status and HER2-neu status was determined by logistic regression with multivariate analysis. Odds ratio (OR), and 95\% confidence interval (CI) were also calculated. Two-sided p values were calculated. Differences and correlations were considered significant if $\mathrm{p}$ value was $<$ $0.05(*),<0.01\left(^{* * *}\right)$ and $<0.001\left(^{(* * *)}\right.$.

\section{Results}

Clinico-pathological characteristics of AA and CAU breast cancer

Clinico-pathological characteristics of breast cancer patients are summarized in Table 1 . Of 173 breast cancer patients, there were $95 \mathrm{CAU}$ and $78 \mathrm{AA}$ women. In both ethnic groups, there was relatively equal distribution of age at diagnosis [diagnosed with breast cancer at age greater than 50 years (CAU 69.5\% vs. AA 70.5\%; $\mathrm{p}=0.99)$ ]. The predominant histological type was ductal adenocarcinoma (CAU $77.8 \%$ vs. AA 97.4\%; $\mathrm{p}=0.003$ ), and there was no statistical difference in histological grade between the two ethnic groups $(p=0.069)$. AA women presented with a significantly lower proportion of smaller size tumors (T1) compared to CAU women (AA $43.6 \%$ vs. CAU 72.6\%; $\mathrm{p}=0.026$ ). However, no statistical difference was found in clinical staging or nodal status at presentation between the two ethnic groups (Table 1). Breast cancers in AA women were ER Negative in larger proportions (38.5\%) compared to the CAU patients $(15.8 \%, \mathrm{p}=0.001)$, whereas there was no difference in PR expression ( $\mathrm{p}=$ 0.081). More than three fourths of all patients were HER-2 negative, and there was no significant difference between the AA and CAU patients $(\mathrm{p}=0.13)$. One third of all AA patients showed negative markers for ER, PR and HER-2 neu (triple negative), compared to only $10.5 \%$ of CAU patients $(\mathrm{p}=0.0008)$.

\section{Overall ALCAM expression in AA and CAU breast cancer tumors}

Immunohistochemical analysis of ALCAM was performed to determine its subcellular localization and level of expresssion in primary breast tumors of AA and CAU women. ALCAM was locliazed to intercellualr junctions/membrane and the cytoplasm. The stain intensity 
ranged from light to dark brown and was scored as 3+ positive (very strong), $2+$ positive (clear staining but not as strong as $3+$ ), 1+ positive (some lighter staining), and negative (no staining) (Figure 1). We developed a Immunoreactive Score (IRS) by combining both intensity of IHC and percentage of ALCAM-positive tumor cells. ALCAM expression in CAU and AA breast cancer tissue is listed in Table 2. There were significant differences in membrane ALCAM expression between the two ethnic groups, with a higher proportion of higher scores (IRS 8-12) in CAU as compared to AA (CAU 85.2\% vs. AA 53.8\%; p < 0.0001) (Figure 2). Notably, there was a higher proportion of negative membranous staining in AA patients as compared to CAU patients (AA 16.7\% vs. CAU 3.2\%). However, there was no difference in the degree of cytoplasmic ALCAM staining between the two groups $(p=0.06)$.

\section{ALCAM and clinical characteristics of AA and CAU breast cancer}

We examined membranous ALCAM in the context of patient characteristics and tumor pathology. Poorly differentiated tumors showed lower intensity membranous staining (IRS 0-7) (AA: p = 0.04; CAU: p = 0.02) (Table 3). An increase in membranous ALCAM expression associated with positive ER status (AA: $\mathrm{p}=0.0004$; CAU: $\mathrm{p}=$ $0.0015)$ and PR status (AA: $\mathrm{p}=0.002$; CAU: $\mathrm{p}=0.034$ ) in both ethnic groups. Most notably triple negative tumors
(TN: ER, PR, and HER-2 neu negative) showed significantly lower intensity membranous staining (IRS 0-7) as compared to tumors that were not triple negative in both ethnic groups (AA; $\mathrm{p}=0.0002 ; \mathrm{CAU} ; \mathrm{p}=0.0006$ ). There was no significant correlation with the membranous pattern of staining and age of the patient, histological tumor type, tumor size, lymph node status or HER2-neu status in either ethnic group.

\section{Multivariable analysis of ALCAM expression with ethnicity}

Since loss of ALCAM function is a bad prognostic marker in breast cancer, we examined which factors would contribute most significantly to its expression. We built a multivariable logistic regression model to include basal-like subtype, ethnicity and four additional covariates (age, histological grade, tumor size, lymph node status). Table 4 demonstrates that ethnicity contributed significantly to ALCAM expression after adjustment for the other covariates. Compared to CAU, the AA tumors were about 4-times more likely to have low ALCAM expression ( $\mathrm{p}=$ 0.003), after accounting for basal-like status and the other four variables. Basal-like status was associated with ALCAM expression $(\mathrm{p}=0.01)$ however in this model, age (under or above 50 years), histological grade (poorly and well-moderately), tumor size [large $(>2 \mathrm{~cm})$ and small $(\leq 2 \mathrm{~cm})]$, lymph node status, did not contribute to ALCAM expression.

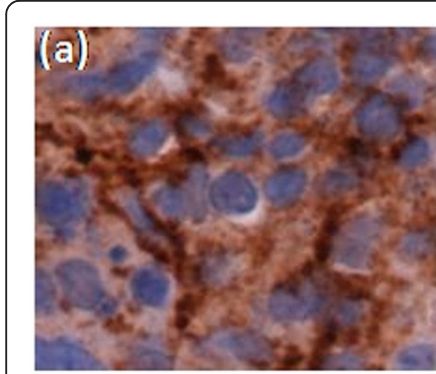

$\mathrm{C} 3+$

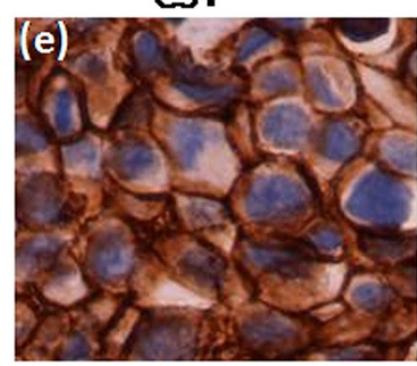

M3+

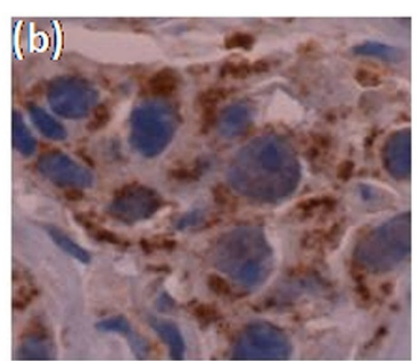

C2+

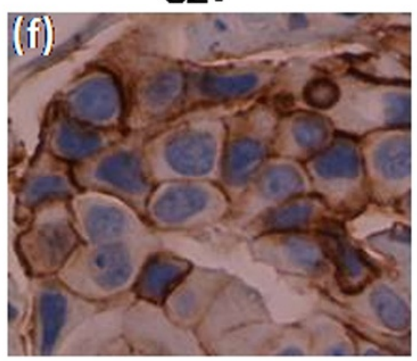

M2+

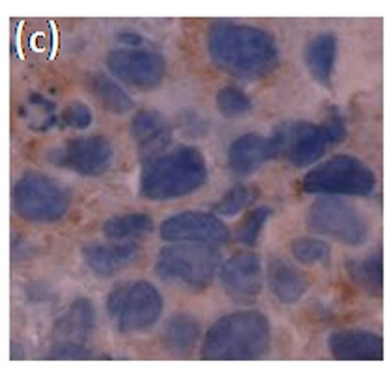

C1+

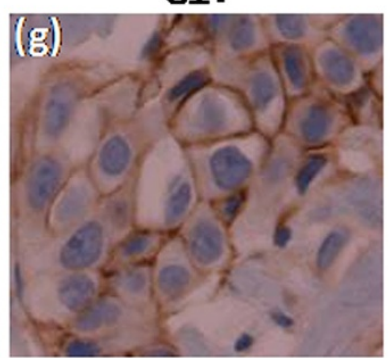

M1+
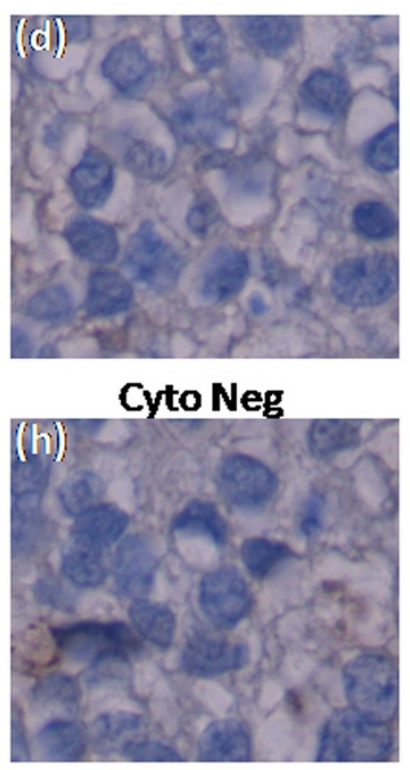

Mem Neg

Figure 1 The intensity of immunohistochemistry staining with ALCAM in breast cancer tissue. (a) C3+ positive: intensity is very strong in cytoplasmic staining. (b) C2+ positive: clear staining but the intensity is not as strong as c3+. (c) C1+ positive: some light cytoplasmic staining. (d) Negative: no staining. (e) M3+ positive: intensity is very strong in membranous staining. (f) M2+ positive: clear staining but the intensity is not as strong as M3+. (g) M1+ positive: some light membranous staining. (h) Negative: no staining. Original magnification, x400. 
Table 2 ALCAM expression in AA and CAU breast cancer

\begin{tabular}{|c|c|c|c|c|c|c|c|}
\hline \multirow[t]{2}{*}{ Ethnicity } & \multicolumn{3}{|c|}{ Membranous staining $\mathrm{n}(\%)$} & \multirow[t]{2}{*}{$p$ value } & \multicolumn{2}{|c|}{ Cytoplasmic staining n (\%) } & \multirow{2}{*}{$\begin{array}{c}p \\
\text { value }\end{array}$} \\
\hline & Negative staining & IRS 1-7 & IRS 8-12 & & IRS 1-7 & IRS 8-12 & \\
\hline$\overline{C A U}(n=95)$ & $3(3.2)$ & $11(11.6)$ & $81(85.2)$ & $<0.0001^{*}$ & 29(30.5) & $66(69.5)$ & 0.06 \\
\hline $\mathrm{AA}(\mathrm{n}=78)$ & $13(16.7)$ & $23(29.5)$ & $42(53.8)$ & & $35(44.9)$ & $43(55.1)$ & \\
\hline
\end{tabular}

CAU: Caucasian, AA: African-American, IRS: immunoreactive score, *Age-adjusted.

\section{Discussion}

ALCAM is emerging as an important molecule in cancer due to its consistent differentiation of aggressive phenotypes, prognosis and response to therapy $[19,23,26]$. The goal of this study was to define for the first time the role of ALCAM in the ethnic disparity of breast cancer in the US. The major findings are that ALCAM expression at the critically important intercellular junctions of primary breast cancer tumors is markedly lower in AA women compared to CAU women, regardless of age, histological grade, tumor size and lymph node involvement, ER/PR and HER2-neu status. These findings suggest that ALCAM may dominantly contribute to the aggressive behavior of breast cancer among AA women.

Breast cancer in AA women is characterized by higher grade, later stage at diagnosis and worse survival rate $[2,27]$. Variations in tumor biology at several stages of the disease process likely contribute to this disparity. Molecular and genetic profiling has revealed inter- and intra-ethnic heterogeneity of breast cancer with varied prognoses and responses to therapy [28-30]. Luminal tumors have the most favorable outcome while Her2overexpressing and basal-like (triple-negative, TN)

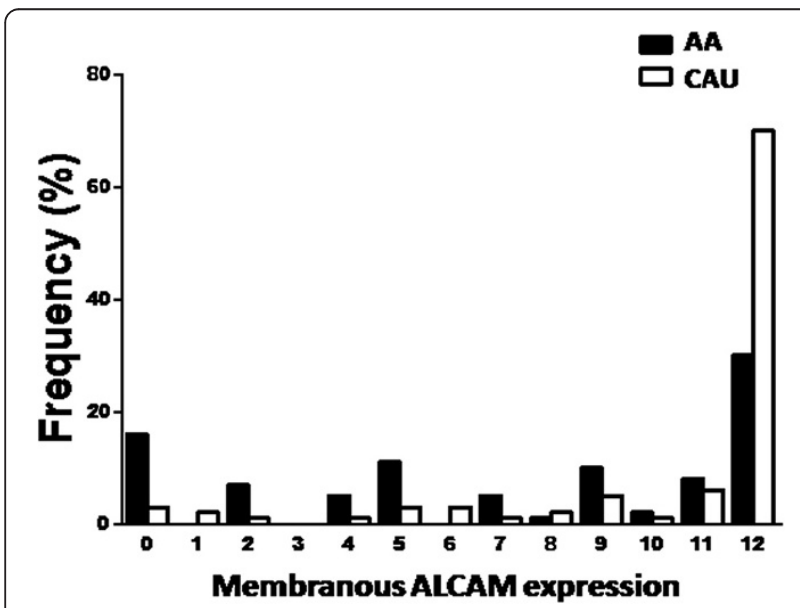

Figure 2 Distribution of membranous ALCAM expression in AA and CAU breast cancer patients. ALCAM levels were determined by immunohistochemistry (IHC) according to the immunoreactive Score (IRS) by combining both intensity of IHC and percentage of tumor cells stained as stated in materials and methods. The $\mathrm{x}$-axis indicates the Membranous ALCAM Immunoreactive score (IRS).

The range of IRS is from 0 (negative staining) to 12. The $y$-axis indicates the frequency of cases. tumors have the worst prognoses [31-34]. Triple-negative tumors are aggressive with a peak risk of recurrence within three years of diagnosis [35,36]. This aggressive subtype is more common in AA women [31,37,38], and contributes to the poor prognosis in young AA women [31]. We confirmed the major ethnic-related histological and molecular phenotypes of breast cancer in our two populations, which provided an important validation of the ethnic categorization of patients, clinicopathological evaluations and the data analyses we used in our study (Table 1). Even after accounting for this major confounder (basal-like subtype), ALCAM expression at intercellular tumor junctions was significantly lower among the AA women with breast cancer (Table 4). These findings reaffirm the prognostic status of ALCAM in breast cancer.

Ethnic differences in ALCAM expression were found when tumors were characterized by histological grade, size and lymph node involvement. ALCAM is thought to contribute to events that influence the transition of homotypic behavior in tumor masses to heterotypic interactions with surrounding cell types. This process is driven in part by proteolytic cleavage of membrane bound ALCAM by ADAM/TACE and its subsequent loss from intercellular tumor junctions [39]. Cytoplasmic overexpression of ALCAM is prognostically relevant in breast cancer [22]. The mechanism responsible for this association of higher cytoplasmic ALCAM levels with a more aggressive course of the disease is not fully addressed. In the current study, we did not find a significant association of cytoplasmic ALCAM expression with ethnicity. We reported recently that ALCAM dominantly influences the adhesive phenotypes of breast cancer cells in the pulmonary vasculature, a process that influences metastasis to the lung. MDA-MB-231 cells, which cannot metastasize to distant sites when injected into the mammary fat pad of athymic nude mice [40,41] formed large ALCAM-mediated homotypic intravascular cell clusters in an isolated perfuse rat lung model. Conversely, ALCAM-negative MDA-MB-435 cells that spontaneously form distant metastasis [40-43] formed similar clusters only after ectopic ALCAM transfer [44,45]. In this study, we found that most AA tumors had low or complete loss of ALCAM expression at intercellular junctions regardless of the basal-like status, level of differentiation, tumor size, lymph node involvement and age (Table 4). Compared to CAU tumors, The AA are about 4 
Table 3 Membranous ALCAM expression and clinical and histological tumor characteristics of AA and CAU breast cancer

\begin{tabular}{|c|c|c|c|c|c|c|}
\hline & \multicolumn{3}{|c|}{ Membranous ALCAM $(n, \%)$ in Caucasian } & \multicolumn{3}{|c|}{ Membranous ALCAM $(n, \%)$ in African American } \\
\hline & IRS 0-7 & IRS 8-12 & $p$ value & IRS 0-7 & IRS 8-12 & $p$ value \\
\hline Age in years & & & 0.41 & & & 0.65 \\
\hline$\leq 50$ & $3(3.1)$ & $26(27.4)$ & & $10(12.8)$ & 13(16.7) & \\
\hline$>50$ & 11(11.6) & $55(57.9)$ & & $27(34.6)$ & 28(35.9) & \\
\hline Histological Type & & & 0.38 & & & 0.93 \\
\hline IDC & 10(11.4) & $64(72.7)$ & & $36(46.2)$ & 40(51.3) & \\
\hline ILC & $0(0)$ & $7(8)$ & & $1(1.3)$ & $1(1.3)$ & \\
\hline IDC\&ILC & $1(1.1)$ & $6(6.8)$ & & $0(0)$ & $0(0)$ & \\
\hline Histological Grade & & & $0.02^{*}$ & & & $0.04^{*}$ \\
\hline G1 & $3(3.3)$ & $26(28.9)$ & & $5(7.2)$ & 11(15.9) & \\
\hline G2 & $3(3.3)$ & $41(45.6)$ & & $11(15.9)$ & 18(26.1) & \\
\hline G3 & $6(6.7)$ & $11(12.2)$ & & $16(23.2)$ & $8(11.6)$ & \\
\hline Tumor size & & & 0.71 & & & 0.82 \\
\hline $\mathrm{T} 1$ & $9(10)$ & $60(66.7)$ & & 15(24.6) & 19(31.1) & \\
\hline $\mathrm{T} 2$ & $3(3.3)$ & 12(13.3) & & $9(14.8)$ & 11(18.0) & \\
\hline T3-T4 & $1(1.1)$ & $5(5.5)$ & & $4(6.6)$ & $3(4.9)$ & \\
\hline Lymph node status & & & 0.95 & & & 0.44 \\
\hline Negative & $6(8.2)$ & $42(57.5)$ & & $16(26.2)$ & $22(36.1)$ & \\
\hline Positive & $3(4.1)$ & $22(30.1)$ & & $12(19.7)$ & $11(18)$ & \\
\hline ER status & & & $0.0015^{*}$ & & & $0.0004^{*}$ \\
\hline Negative & $7(8.2)$ & $8(9.4)$ & & $21(28)$ & $9(12)$ & \\
\hline Positive & $6(7.1)$ & $64(75.3)$ & & 13(17.3) & $32(42.7)$ & \\
\hline PR status & & & $0.034^{*}$ & & & $0.002^{*}$ \\
\hline Negative & $8(8.9)$ & $20(23.5)$ & & $22(29.3)$ & $12(16)$ & \\
\hline Positive & $5(5.9)$ & $52(61.2)$ & & $12(16)$ & 29(38.7) & \\
\hline HER2-neu status & & & 0.14 & & & 0.096 \\
\hline Negative & $12(14)$ & 55(63.9) & & $31(41.9)$ & $34(45.9)$ & \\
\hline Positive & $1(1.2)$ & 18(20.9) & & $2(2.7)$ & $7(9.5)$ & \\
\hline Triple Negative & & & $0.0006^{*}$ & & & $0.0002^{*}$ \\
\hline Yes & $6(7.1)$ & $4(4.8)$ & & $19(25)$ & $6(7.9)$ & \\
\hline No & $7(8.3)$ & $67(79.8)$ & & 16(21.1) & $35(46.1)$ & \\
\hline
\end{tabular}

*Age-adjusted.

times more likely to have low ALCAM expression ( $\mathrm{p}=$ 0.003). ALCAM expression was high in virtually all well-differentiated tumors in CAU women while nearly one-third of tumors of the same level of differentiation in AA women had low ALCAM. This discordance revealed that well-differentiated tumors in AA women are equivalent in number to poorly differentiated tumors in CAU women with respect to ALCAM expression.

It is thought that the level of differentiation of breast cancer tumors influences their overall aggressive phenotype. A lower proportion of breast cancer among the AA women in our study was well differentiated as expected (CAU 76.8\% vs AA 57.7\%). In addition, we uncovered a new source of biological variation (i.e. reducing ALCAM expression), which suggests that well differentiated tumors may adopt a more aggressive phenotype uniquely among AA women. This assertion is based on results showing low ALCAM expression in significantly higher number of well differentiated tumors in this patient population. Overall, our data suggests that compared to CAU women, breast cancer tumors of equivalent size and histological grade in AA women are more likely to lose homotypic 
Table 4 Multivariable logistic regression analysis of the association between ethnicity and ALCAM expression in breast cancer

\begin{tabular}{|c|c|c|c|c|}
\hline & \multicolumn{2}{|c|}{$\begin{array}{c}\text { Membranous ALCAM } \\
\text { level } \mathbf{n}(\%)\end{array}$} & \multirow[b]{2}{*}{$\begin{array}{l}\text { Odds ratio } \\
(95 \% \mathrm{Cl})\end{array}$} & \multirow[b]{2}{*}{$P$ value } \\
\hline & IRS 0-7 & IRS 8-12 & & \\
\hline \multicolumn{5}{|l|}{ Ethnicity } \\
\hline $\mathrm{AA}$ & 37 (72.55) & $41(33.61)$ & $4.28(1.64-11.15)$ & 0.003 \\
\hline CAU & $14(27.45)$ & 81 (66.39) & Reference & \\
\hline \multicolumn{5}{|l|}{ Age in years } \\
\hline$\leq 50$ & $13(25.49)$ & $39(31.97)$ & $0.69(0.24-1.99)$ & 0.49 \\
\hline$>50$ & $38(74.51)$ & $83(68.03)$ & Reference & \\
\hline \multicolumn{5}{|l|}{ Histological grade } \\
\hline Poor & $22(50.00)$ & 19 (16.52) & $2.10(0.60-7.34)$ & 0.25 \\
\hline Well-moderately & $22(50.00)$ & $96(83.48)$ & Reference & \\
\hline \multicolumn{5}{|l|}{ Tumor size } \\
\hline Large $(>2 \mathrm{~cm})$ & $17(41.46)$ & $31(28.18)$ & $0.62(0.20-1.88)$ & 0.39 \\
\hline Small $(\leq 2 \mathrm{~cm})$ & $24(58.54)$ & 79 (71.82) & Reference & \\
\hline \multicolumn{5}{|l|}{ Lymph node } \\
\hline Positive & $15(40.54)$ & 33 (34.02) & $1.62(0.58-4.54)$ & 0.36 \\
\hline Negative & $22(59.46)$ & $64(65.98)$ & Reference & \\
\hline \multicolumn{5}{|l|}{ Basal-like (TN) } \\
\hline Yes & $25(51.02)$ & $10(8.85)$ & $5.59(1.46-21.50)$ & 0.01 \\
\hline No & $24(48.98)$ & $103(91.15)$ & Reference & \\
\hline
\end{tabular}

adhesions within the tumor mass, which would promote their metastatic potential.

\section{Conclusions}

ALCAM expression at intercellular tumor junctions correlates with tumor grade, ER status, PR status and triple-negative tumor status in breast cancer patients. Down-regulation of ALCAM is more severe in AA women than in CAU women even when the tumors have identical characteristics, such as histological grade, tumor size and lymph involvement. Lower ALCAM expression may contribute to the aggressive phenotype of breast cancer among AA women.

\section{Abbreviations}

ALCAM: Activated leukocyte cell adhesion molecule; AA: African-American; CAU: Caucasian; FFPE: Formalin-fixed paraffin-embedded; IRS: Immunoreactive score; ER: Estrogen receptor; PR: Progesterone receptor; HER2: Human epidermal growth receptor 2; TN: Triple negative.

\section{Competing interests}

The authors declare that they have no competing of interests.

\section{Authors' contributions}

FT performed the experiments, analyzed data and wrote the manuscript, MM and ALA designed experiments, analyzed the data and wrote the manuscript; BA and OT extracted and compiled the clinical data, YH performed statistical analysis, MR collected samples and clinical data, SFOA designed the study and supervised the project, analyzed data and wrote the manuscript. All authors read and approved the final manuscript.

\section{Acknowledgements}

We thank clinical coordinators for providing database support and Dianne Alexis for guidance with the immunohistochemical staining. We acknowledge the technical and programming assistance of University of South Alabama. This work was supported by NIH grants R01HL077769 and P20MD002314

\section{Author details}

1 Aflac Cancer Center and Blood Disorders Service, Department of Pediatrics, Emory University School of Medicine, 2015 Uppergate Drive, Atlanta, GA 30322, USA. ${ }^{2}$ Grady Memorial Hospital, Atlanta, GA, USA. ${ }^{3}$ Department of Pathology and Laboratory Medicine, Emory University School of Medicine, Atlanta, GA, USA. ${ }^{4}$ Department of Biostatistics and Bioinformatics, Rollins School of Public Health, Emory University, Atlanta, GA, USA. ${ }^{5}$ Department of Surgery, Division of Surgical Oncology, Emory University School of Medicine, Atlanta, GA, USA. ${ }^{6}$ Current address: University of Pittsburgh, 200 Lothrop Street, Pittsburgh, PA 15261, USA.

Received: 9 September 2013 Accepted: 22 September 2014 Published: 25 September 2014

\section{References}

1. Jemal A, Siegel R, Xu J, Ward E: Cancer statistics, 2010. CA Cancer J Clin 2010, 60(5):277-300.

2. Eley JW, Hill HA, Chen WW, Austin DF, Wesley MN, Muss HB, Greenberg RS, Coates RJ, Correa P, Redmond CK, Hunter CP, Herman AA, Kurman RJ, Blacklow RS, Shapiro S, Edwards BK: Racial differences in survival from breast cancer. Results of the National Cancer Institute Black/White Cancer Survival Study. JAMA 1994, 272(12):947-954.

3. Elledge RM, Clark GM, Chamness GC, Osborne CK: Tumor biologic factors and breast cancer prognosis among white, Hispanic, and black women in the United States. J Natl Cancer Inst 1994, 86(9):705-712.

4. Ademuyiwa FO, Edge SB, Erwin DO, Orom H, Ambrosone CB, Underwood W: 3rd: breast cancer racial disparities: unanswered questions. Cancer Res 2011, 71(3):640-644.

5. Hunter CP, Redmond CK, Chen WW, Austin DF, Greenberg RS, Correa P, Muss HB, Forman MR, Wesley MN, Blacklow RS, Kurman RJ, Dignam JJ, Edwards BK, Shapiro S: Breast cancer: factors associated with stage at diagnosis in black and white women. Black/White Cancer Survival Study Group. J Natl Cancer Inst 1993, 85(14):1129-1137.

6. Zaloznik AJ: Breast cancer stage at diagnosis: Caucasians versus Afro-Americans. Breast Cancer Res Treat 1995, 34(3):195-198.

7. Hayes DF, Isaacs C, Stearns V: Prognostic factors in breast cancer: current and new predictors of metastasis. J Mammary Gland Biol Neoplasia 2001, 6(4):375-392.

8. Isaacs C, Stearns $V$, Hayes DF: New prognostic factors for breast cancer recurrence. Semin Oncol 2001, 28(1):53-67.

9. Parker C, Rampaul RS, Pinder SE, Bell JA, Wencyk PM, Blamey RW, Nicholson $\mathrm{Rl}$, Robertson JF: E-cadherin as a prognostic indicator in primary breast cancer. Br J Cancer 2001, 85(12):1958-1963.

10. Berx G, Van Roy F: The E-cadherin/catenin complex: an important gatekeeper in breast cancer tumorigenesis and malignant progression. Breast Cancer Res 2001, 3(5):289-293.

11. Clavel CE, Nollet F, Berx G, Tejpar S, Nawrocki-Raby B, Kaplan HH, van Roy FM, Birembaut PL: Expression of the E-cadherin-catenin complex in lung neuroendocrine tumours. J Pathol 2001, 194(1):20-26.

12. Bracke ME, Charlier C, Bruyneel EA, Labit C, Mareel MM, Castronovo V: Tamoxifen restores the E-cadherin function in human breast cancer MCF-7/6 cells and suppresses their invasive phenotype. Cancer Res 1994 54(17):4607-4609.

13. Bowen MA, Patel DD, Li X, Modrell B, Malacko AR, Wang WC, Marquardt H, Neubauer M, Pesando JM, Francke U, Haynes BF, Aruffo A: Cloning, mapping, and characterization of activated leukocyte-cell adhesion molecule (ALCAM), a CD6 ligand. J Exp Med 1995, 181(6):2213-2220.

14. Bowen MA, Bajorath J, D'Egidio M, Whitney GS, Palmer D, Kobarg J, Starling GC, Siadak AW, Aruffo A: Characterization of mouse ALCAM (CD166): the CD6-binding domain is conserved in different homologs and mediates cross-species binding. Eur J Immunol 1997, 27(6):1469-1478. 
15. Corbel C, Cormier F, Pourquie O, Bluestein HG: BEN, a novel surface molecule of the immunoglobulin superfamily on avian hemopoietic progenitor cells shared with neural cells. Exp Cell Res 1992, 203(1):91-99.

16. Tan F, Mbunkui F, Ofori-Acquah SF: Cloning of the human activated leukocyte cell adhesion molecule promoter and identification of its tissue-independent transcriptional activation by Sp1. Cell Mol Biol Lett 2012, 17(4):571-585.

17. Masedunskas A, King JA, Tan F, Cochran R, Stevens T, Sviridov D, Ofori-Acquah SF: Activated leukocyte cell adhesion molecule is a component of the endothelia junction involved in transendothelial monocyte migration. FEBS Lett 2006 580(11):2637-2645.

18. King JA, Ofori-Acquah SF, Stevens T, Al-Mehdi AB, Fodstad O, Jiang WG: Activated leukocyte cell adhesion molecule in breast cancer: prognostic indicator. Breast Cancer Res 2004, 6(5):R478-R487.

19. King JA, Tan F, Mbeunkui F, Chambers Z, Cantrell S, Chen H, Alvarez D, Shevde LA, Ofori-Acquah SF: Mechanisms of transcriptional regulation and prognostic significance of activated leukocyte cell adhesion molecule in cancer. Mol Cancer 2010, 9:266

20. Jezierska A, Matysiak W, Motyl T: ALCAM/CD166 protects breast cancer cells against apoptosis and autophagy. Med Sci Monit 2006, 12(8):BR263-BR273.

21. Jezierska A, Olszewski WP, Pietruszkiewicz J, Olszewski W, Matysiak W, Motyl T: Activated Leukocyte Cell Adhesion Molecule (ALCAM) is associated with suppression of breast cancer cells invasion. Med Sci Monit 2006, 12(7):BR245-BR256.

22. Burkhardt M, Mayordomo E, Winzer KJ, Fritzsche F, Gansukh T, Pahl S, Weichert W, Denkert C, Guski H, Dietel M, Kristiansen G: Cytoplasmic overexpression of ALCAM is prognostic of disease progression in breast cancer. J Clin Pathol 2006, 59(4):403-409.

23. Ofori-Acquah SF, King JA: Activated leukocyte cell adhesion molecule: a new paradox in cancer. Transl Res 2008, 151(3):122-128.

24. Davies SR, Dent C, Watkins G, King JA, Mokbel K, Jiang WG: Expression of the cell to cell adhesion molecule, ALCAM, in breast cancer patients and the potential link with skeletal metastasis. Oncol Rep 2008, 19(2):555-561.

25. Singletary SE, Allred C, Ashley P, Bassett LW, Berry D, Bland Kl, Borgen Pl, Clark G, Edge SB, Hayes DF, Hughes LL, Hutter RV, Morrow M, Page DL, Recht A, Theriault RL, Thor A, Weaver DL, Wieand HS, Greene FL: Revision of the American Joint Committee on Cancer staging system for breast cancer. J Clin Oncol 2002, 20(17):3628-3636.

26. Tan F, Ghosh S, Mbeunkui F, Thomas R, Weiner JA, Ofori-Acquah SF: Essential role for ALCAM gene silencing in megakaryocytic differentiation of K562 cells. BMC Mol Biol 2010, 11:91

27. Furberg H, Millikan R, Dressler L, Newman B, Geradts J: Tumor characteristics in African American and white women. Breast Cancer Res Treat 2001, 68(1):33-43.

28. Reis-Filho JS, Simpson PT, Gale T, Lakhani SR: The molecular genetics of breast cancer: the contribution of comparative genomic hybridization. Pathol Res Pract 2005, 201(11):713-725.

29. Lacroix M, Toillon RA, Leclercq G: Stable 'portrait' of breast tumors during progression: data from biology, pathology and genetics. Endocr Relat Cancer 2004, 11(3):497-522.

30. Perou CM, Sorlie T, Eisen MB, van de Rijn M, Jeffrey SS, Rees CA, Pollack JR, Ross DT, Johnsen $H$, Akslen LA, Fluge O, Pergamenschikov A, Williams C, Zhu SX, Lønning PE, Børresen-Dale AL, Brown PO, Botstein D: Molecular portraits of human breast tumours. Nature 2000, 406(6797):747-752.

31. Carey LA, Perou CM, Livasy CA, Dressler LG, Cowan D, Conway K, Karaca G, Troester MA, Tse CK, Edmiston S, Deming SL, Geradts J, Cheang MC, Nielsen TO, Moorman PG, Earp HS, Millikan RC: Race, breast cancer subtypes, and survival in the Carolina Breast Cancer Study. JAMA 2006, 295(21):2492-2502.

32. Nielsen TO, Hsu FD, Jensen $K$, Cheang M, Karaca G, Hu Z, Hernandez-Boussard T, Livasy C, Cowan D, Dressler L, Akslen LA, Ragaz J, Gown AM, Gilks CB, van de Rijn M, Perou CM: Immunohistochemical and clinical characterization of the basal-like subtype of invasive breast carcinoma. Clin Cancer Res 2004, 10(16):5367-5374.

33. Rakha EA, El-Rehim DA, Paish C, Green AR, Lee AH, Robertson JF, Blamey RW Macmillan D, Ellis IO: Basal phenotype identifies a poor prognostic subgroup of breast cancer of clinical importance. Eur J Cancer 2006, 42(18):3149-3156.

34. Sorlie T, Perou CM, Tibshirani R, Aas T, Geisler S, Johnsen H, Hastie T, Eisen MB, van de Rijn M, Jeffrey SS, Thorsen T, Quist H, Matese JC, Brown PO, Botstein D, Lønning PE, Børresen-Dale AL: Gene expression patterns of breast carcinomas distinguish tumor subclasses with clinical implications. Proc Nat/ Acad Sci U S A 2001, 98(19):10869-10874.
35. Dent R, Trudeau M, Pritchard KI, Hanna WM, Kahn HK, Sawka CA, Lickley LA, Rawlinson E, Sun P, Narod SA: Triple-negative breast cancer: clinical features and patterns of recurrence. Clin Cancer Res 2007, 13(15 Pt 1):4429-4434.

36. Tischkowitz M, Brunet JS, Begin LR, Huntsman DG, Cheang MC, Akslen LA, Nielsen TO, Foulkes WD: Use of immunohistochemical markers can refine prognosis in triple negative breast cancer. BMC Cancer 2007, 7:134

37. Bauer KR, Brown M, Cress RD, Parise CA, Caggiano V: Descriptive analysis of estrogen receptor (ER)-negative, progesterone receptor (PR)-negative, and HER2-negative invasive breast cancer, the so-called triple-negative phenotype: a population-based study from the California cancer Registry. Cancer 2007, 109(9):1721-1728.

38. Morris GJ, Naidu S, Topham AK, Guiles F, Xu Y, McCue P, Schwartz GF, Park PK, Rosenberg AL, Brill K, Mitchell EP: Differences in breast carcinoma characteristics in newly diagnosed African-American and Caucasian patients: a single-institution compilation compared with the National Cancer Institute's Surveillance, Epidemiology, and End Results database. Cancer 2007, 110(4):876-884

39. Micciche F, Da Riva L, Fabbi M, Pilotti S, Mondellini P, Ferrini S, Canevari S, Pierotti MA, Bongarzone I: Activated leukocyte cell adhesion molecule expression and shedding in thyroid tumors. PLOS One 2011, 6(2):e17141.

40. Fillmore RA, Mitra A, Xi Y, Ju J, Scammell J, Shevde LA, Samant RS: Nmi (N-Myc interactor) inhibits Wnt/beta-catenin signaling and retards tumor growth. Int J Cancer 2009, 125(3):556-564.

41. Mitra A, Fillmore RA, Metge BJ, Rajesh M, Xi Y, King J, Ju J, Pannell L, Shevde LA, Samant RS: Large isoform of MRJ (DNAJB6) reduces malignant activity of breast cancer. Breast Cancer Res 2008, 10(2):R22.

42. Shevde LA, Samant RS, Paik JC, Metge BJ, Chambers AF, Casey G, Frost AR, Welch DR: Osteopontin knockdown suppresses tumorigenicity of human metastatic breast carcinoma, MDA-MB-435. Clin Exp Metastasis 2006, 23(2):123-133.

43. Samant RS, Seraj MJ, Saunders MM, Sakamaki TS, Shevde LA, Harms JF, Leonard TO, Goldberg SF, Budgeon L, Meehan WJ, Winter CR, Christensen ND, Verderame MF, Donahue HJ, Welch DR: Analysis of mechanisms underlying BRMS1 suppression of metastasis. Clin Exp Metastasis 2000, 18(8):683-693.

44. Al-Mehdi AB, Tozawa K, Fisher AB, Shientag L, Lee A, Muschel RJ: Intravascular origin of metastasis from the proliferation of endothelium-attached tumor cells: a new model for metastasis. Nat Med 2000, 6(1):100-102

45. Wong CW, Song C, Grimes MM, Fu W, Dewhirst MW, Muschel RJ, Al-Mehdi AB: Intravascular location of breast cancer cells after spontaneous metastasis to the lung. Am J Pathol 2002, 161(3):749-753.

doi:10.1186/1471-2407-14-715

Cite this article as: Tan et al.: Enhanced down-regulation of ALCAM/

CD166 in African-American Breast Cancer. BMC Cancer 2014 14:715.

\section{Submit your next manuscript to BioMed Central and take full advantage of:}

- Convenient online submission

- Thorough peer review

- No space constraints or color figure charges

- Immediate publication on acceptance

- Inclusion in PubMed, CAS, Scopus and Google Scholar

- Research which is freely available for redistribution

Submit your manuscript at www.biomedcentral.com/submit
C) Biomed Central 